\title{
Subliminal Affective Priming Effect on Decision Making in Prisoner's Dilemma
}

\author{
Juan LIU ${ }^{1, a}$, Hua-Miao SONG ${ }^{1, b^{*}}$, Wen DONG ${ }^{2, c}$, Wen-Hua PENG ${ }^{2, d}$, \\ Feng $\mathrm{SHAO}^{2, \mathrm{e}}$, Liu YANG ${ }^{1, f}$ and Yi-Shuang ZHANG ${ }^{1, g}$ \\ ${ }^{1}$ Institute of Aviation Medicine, Air Force, Beijing, 100142, China \\ ${ }^{2}$ Dujiangyan Aviation Medicine Training Center of Air Force, Sichuan 611800, China \\ alj-wxj@163.com, bshmiaoj@163.com, dongwen@189.cn, ${ }^{\mathrm{a}}$ pengwh@163.com, ${ }^{\mathrm{e}}$ shaof@163.com,

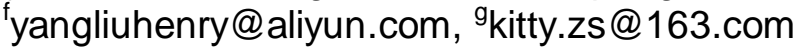 \\ ${ }^{*}$ Corresponding author
}

Keywords: Subliminal perception, Emotional faces, Decision-making, Prisoners' Dilemma (PD), egoism, altruism.

\begin{abstract}
Is subliminal priming able to affect people's choices and decision-making? The prisoners' dilemma is a canonical example of a game analyzed that shows why two individuals might not cooperate each other, even if it appears that it is in their best interest to do so. In the regular version of the prisoner's dilemma game, collaboration is dominated by betrayal, and as a result, the only possible outcome of the game is for both prisoners to betray the other. Regardless of what the other prisoner chooses one will always gain a greater payoff by betraying the other. Because betrayal is always more beneficial than cooperation, all objective prisoners would seemingly betray the other. This study examined whether subliminal emotional faces influence human's decision-making in the repeated prisoners' dilemma. In this study, subliminal emotional face was the independent variable. According to different emotional valence (happy, neutral or angry) and different present way of emotional faces (a transparent figure, or a backward masking face), the independent variable has 7 levels. So, 84 undergraduates were randomly divided into seven groups, participants in each group were subliminally primed with one kind of unseen face, after which they completed pre-designed negotiations task. The results showed that whatever the way to show subliminal emotional faces: by a transparent figure, or backward masking, both affected human's decision-making. Under the influence of different ways to present subliminal faces, participants choose their own behavior more cooperative or more uncooperative. These findings contribute to subliminal perception research on decision-making and the implications for this study are discussed.
\end{abstract}

\section{Introduction}

In the real world, each person keeps trying his best to pursue the maximum interests for himself. Therefore, the game between people is often uncooperative and betrayal is always the most optimal policy for rational people [1]. This desire that everyone makes his effort to achieve the greatest interest leads to the "Prisoner's Dilemma" (PD), which is the common problem in the modern society [2]. In the regular version of this game, collaboration is dominated by betrayal, and as a result, the only possible outcome of the game is for both prisoners to betray the other. Regardless of what the other prisoner chooses, one will always gain a greater payoff by betraying the other. Because betrayal is always more beneficial than cooperation, all objective prisoners would seemingly betray the other if operating purely rationally. The problem with the prisoner's dilemma is that if both decision-makers were purely rational, they would never cooperate. Indeed, rational decision-making means that you make the decision which is best for you whatever the other actor chooses.

This research builds an uncooperative game situation to investigate the influence of subliminal emotional faces on the players' decision-making and behavior, which will provide a unique entrance to 
get rid of the embarrassment of "Prisoners' Dilemma". Since human nature has both the characteristic of egoism and altruism, this research aims to put forward a new way that can influence human's decision-making strategies during Prisoners' Dilemma game. By this way, players' ideal individual rationality and collective rationality can be guided in game.

\section{METHOD}

The finitely repeated Prisoners' Dilemma game model was used as the negotiations task in this research. Every participant was asked to complete the same task six times.

\section{Participants}

The section headings are in boldface capital and lowercase letters. Second level headings are typed as part of the succeeding paragraph (like the subsection heading of this paragraph). 84 participants recruited for this experiment are college students and all of them have normal visual acuity (or corrected visual acuity) and auditory acuity, between 18 and 25 years old. The age and gender distribution of the participants is provided in Table 1. All the 84 participants were strangers and they did not take part in such negotiations experiment in the past. Participants were asked to sign an informed consent form before commencing testing, and were paid for their participation. The whole test session lasted about $10 \mathrm{~min}$.

Table 1 Characterization of participants

\begin{tabular}{ccc}
\hline Gender & Number & Average age(years) \\
\hline male & 42 & $22.94 \pm 1.81$ \\
female & 42 & $21.83 \pm 1.47$ \\
\hline
\end{tabular}

\section{Apparatus}

The experiment was presented and completed by Lenovo computer (Intel Pentium 4) and the mouse was used to respond. The Prisoners' Dilemma game situation and the subliminal stimuli were displayed by the 17 -inch LCD monitor (with a refresh rate of $75 \mathrm{~Hz}$ and resolution of $1024 * 768$ pixels).

\section{Experimental materials}

We chose 18 facial expression pictures (half male and half female) from the Chinese Facial Affective Picture System (CFAPS) of Professor Yuejia Luo. The 18 facial pictures were composed of 6 happy faces, 6 neutral faces and 6 angry faces. All pictures were set to size $260 * 300$ pixels, showing on the center of the screen. Both the brightness, contrast, and saturation of the screen were adjusted to $50 \%$.

\section{Experimental design}

\section{Independent variables}

The experimental design included two between-subjects independent variables. One variable was emotional valence, including three levels: happy, neutral and angry, the other variable was the present way of emotional faces, including two levels: a transparent figure, or a backward masking face. In addition to a control group, so the independent variable has 7 levels: a transparent happy face, a transparent neutral face, a transparent angry face, a backward masking happy face, a backward masking neutral face, a backward masking angry face and without any figure (control group).

\section{Dependent variables}

The dependent variables used to measure decision-making in this research were the choice rate of black card and the profit/loss value. These two measures allowed for assessing the participant's collaboration in the decision-making process.

\section{Experimental procedures and order of the trials}

The participants were randomly divided into seven groups according to sex and age, each group included 12 members. One group was treated as control group, and the remaining six groups were 
experimental groups, which were respectively treated with the stimuli of different subliminal emotional faces. Participants were seated and received stimuli from the screen of a computer, and then they were asked to finish the pre-designed negotiations task and response by mouse. The distance from the participants' eyes to the computer screen was about $70 \mathrm{~cm}$.

The experimental procedures were programming using VB language. Two subjects came to the laboratory together to participate in the negotiations. Firstly, experiment instruction was presented on the screen: $\mathrm{Hi}$, welcome to the experiment. This is a negotiation experiment, during the whole experiment process you will represent a company. Your task is to negotiate with another company and then make the decision to win the most benefits for your own company. The following is the introduction of the task, please read carefully.

Contract negotiations: After several times of negotiations, the two companies eventually reached an agreement to complete their contract through six transactions.

Contract execution: In the process of implementation of the contract, the two companies need to obey the following rules (the way of decision-making is playing: red card or black card).

Decision rules:

1) There are a total of six deals, you ought to complete a deal then start a next deal until six times.

2) The two companies ought to play at the same time. If both sides play the red card, they will gain 200 thousand Yuan respectively; if both sides play the black card, they will lose 300 thousand Yuan respectively; if one side plays the red card and the other side plays the black card, then the red side will lose 500 thousand Yuan, the black side will gain 500 thousand Yuan.

3) The profit/loss value of the third and sixth round will double.

The two subjects were seated face to face during the negotiation process. All the subliminal emotional faces were presented by the computer screen. The subliminal stimuli had two kind of different present ways: transparent and backward masking. The transparent faces appeared and disappeared at the same time with the fixation (+), lasting $1500 \mathrm{~ms}$. The backward masking faces only lasted $20 \mathrm{~ms}$, appearing after a masking picture. In our experiment, a neutral emotional face was used as the masking picture, which last 300ms.

When the two participants finished the negotiations for six times, experiment thank-you words were presented on the screen: The experiment is over, thank you for your participation and support.

\section{RESULTS}

\section{The choice rate of black card}

The effect of subliminal emotional faces on the choice rate of black card is shown in Figure 1. A one-way analysis of variance was conducted to explore the impact of subthreshold signal on the choice rate of black card. The results showed that there were significant differences in participants' decision-making preferences $(\mathrm{p}=0.001)$. Follow-up pair wise comparisons (LSD Test)of these means yielded significant results $(\mathrm{p}=0.028)$, which is provided in Table 2 . Obviously, the subliminal emotional faces significantly affect the participant's decision-making results: the group of backward masking happy face and the remaining six groups have significant differences, among the seven experimental conditions, participants receiving the backward masking happy face are more inclined to choose red card; and the group of transparent neutral face and the other four groups (without any figure, backward masking happy face, backward masking neutral face, backward masking angry face) have significant differences, participants receiving the transparent neutral face are more inclined to choose black card. 


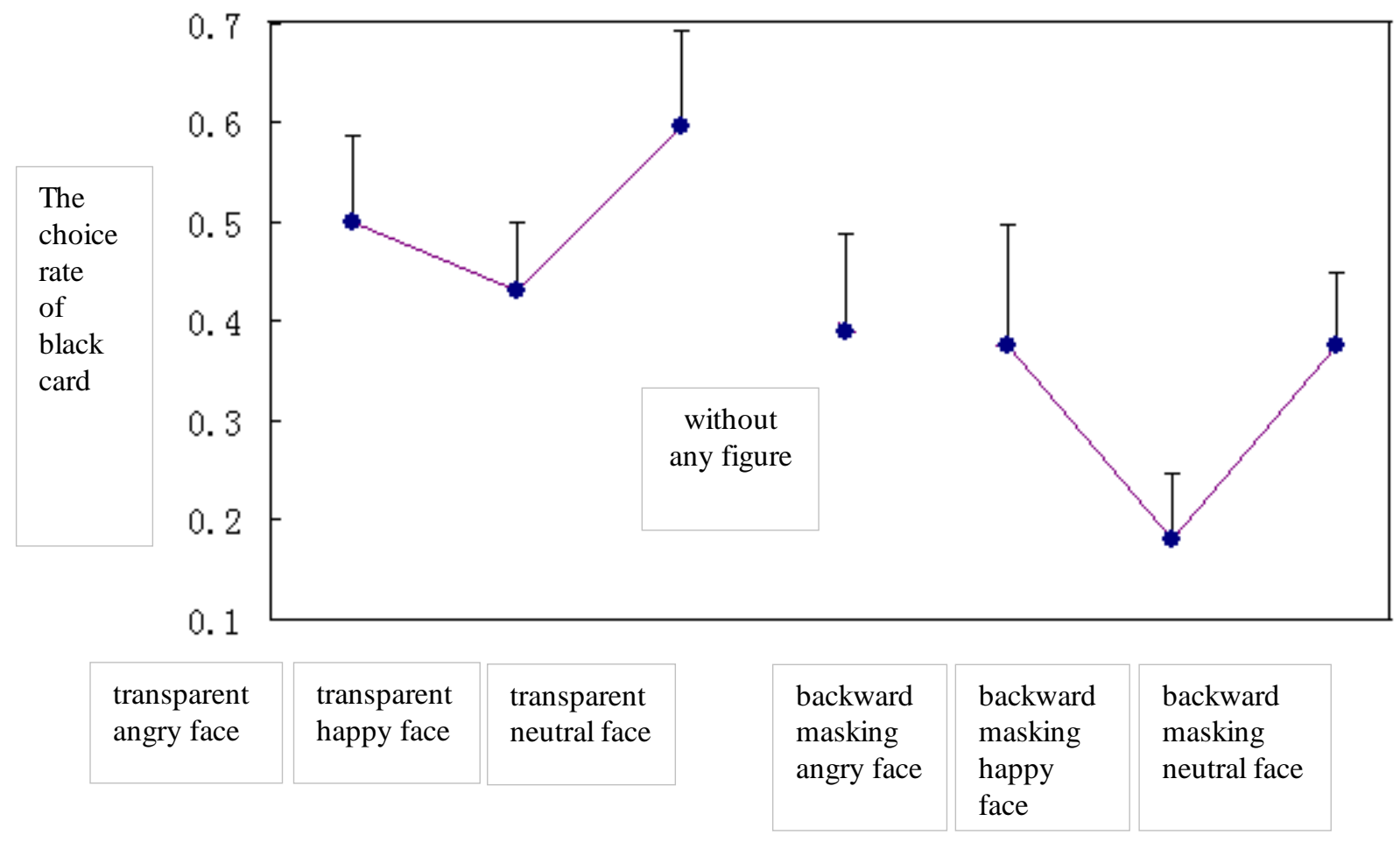

Figure 1 The effect of subliminal emotional faces on the choice rate of black card

Table 2 Multiple comparisons of the effect of emotional faces on the choice rate of black card $(\mathrm{N}=84)$

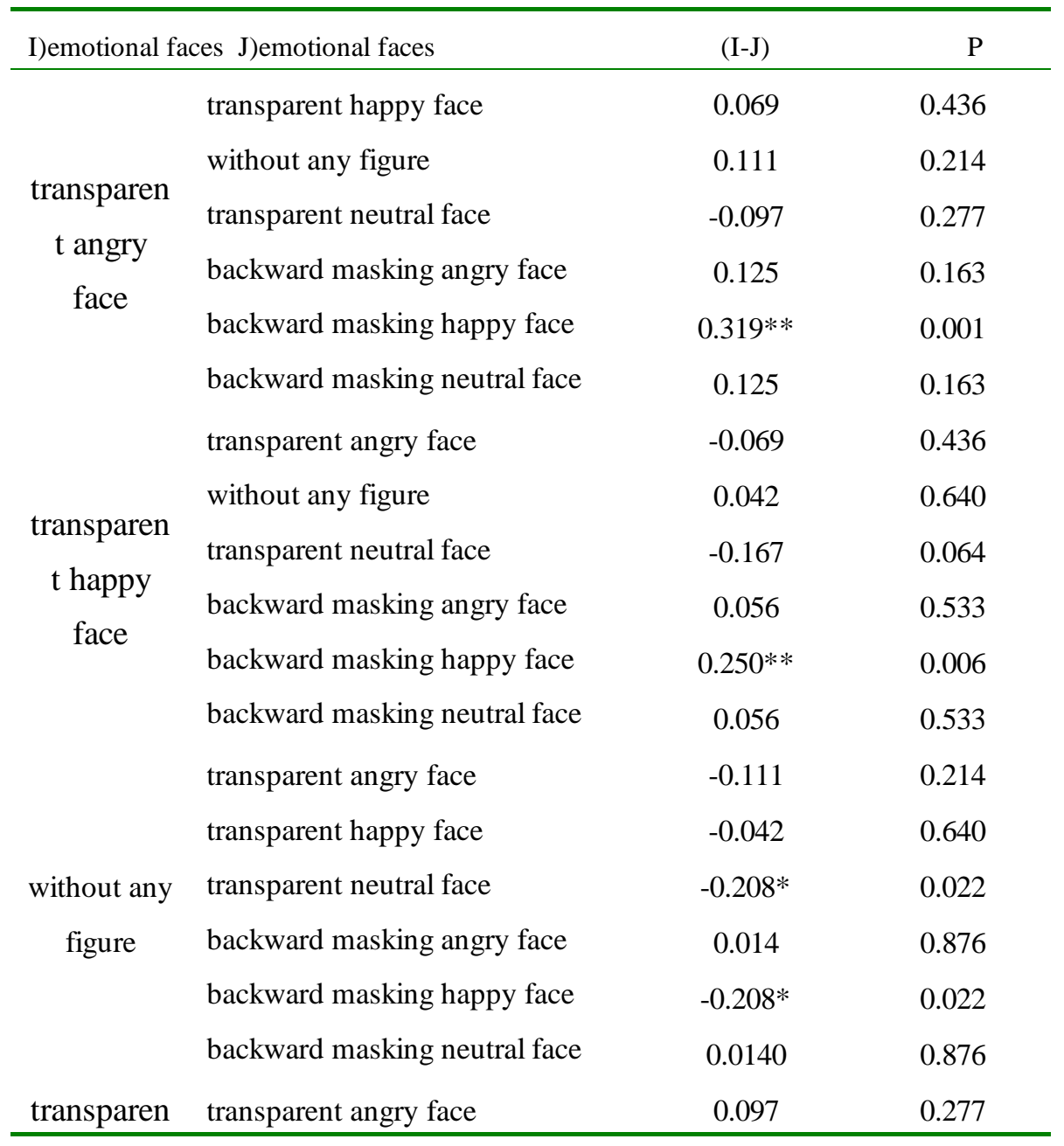




\begin{tabular}{|c|c|c|c|}
\hline \multirow{6}{*}{$\begin{array}{l}\text { t neutral } \\
\text { face }\end{array}$} & transparent happy face & 0.167 & 0.064 \\
\hline & without any figure & $0.208 *$ & 0.022 \\
\hline & backward masking angry face & $0.222 *$ & 0.015 \\
\hline & backward masking happy face & $0.417^{* *}$ & 0.000 \\
\hline & backward masking neutral face & $0.222 *$ & 0.015 \\
\hline & transparent angry face & -0.125 & 0.163 \\
\hline \multirow{6}{*}{$\begin{array}{l}\text { backward } \\
\text { masking } \\
\text { angry face }\end{array}$} & transparent happy face & -0.056 & 0.533 \\
\hline & without any figure transparent & -0.014 & 0.876 \\
\hline & neutral face backward masking & $-0.222 *$ & 0.015 \\
\hline & happy face backward masking & $0.194 *$ & 0.032 \\
\hline & neutral face & 0.000 & 1.000 \\
\hline & transparent angry face & $-0.319 * *$ & 0.001 \\
\hline \multirow{6}{*}{$\begin{array}{l}\text { backward } \\
\text { masking } \\
\text { happy face }\end{array}$} & transparent happy face & $-0.250^{* *}$ & 0.006 \\
\hline & without any figure transparent & $-0.208^{*}$ & 0.022 \\
\hline & neutral face backward masking & $-0.417 * *$ & 0.000 \\
\hline & angry face backward masking & $-0.194 *$ & 0.032 \\
\hline & neutral face & $-0.194 *$ & 0.032 \\
\hline & transparent angry face & -0.125 & 0.163 \\
\hline \multirow{5}{*}{$\begin{array}{c}\text { backward } \\
\text { masking } \\
\text { neutral } \\
\text { face }\end{array}$} & transparent happy face & -0.056 & 0.533 \\
\hline & without any figure transparent & -0.014 & 0.876 \\
\hline & neutral face backward masking & $-0.222 *$ & 0.015 \\
\hline & angry face backward masking & -0.000 & 1.0000 \\
\hline & happy face & $0.194 *$ & 0.032 \\
\hline
\end{tabular}

*significant difference $* *$ very significant difference

\section{Profit/loss value}

The statistical results of profit/loss value are provided in Table 3.

Table 3 The descriptive statistics of profit/loss value $(\mathrm{N}=84)$

\begin{tabular}{lcc}
\hline & $\mathrm{M}$ & $\mathrm{S}$ \\
\hline transparent angry face & (ten thousand Yuan) & (ten thousand Yuan) \\
transparent happy face & -45.000 & 103.087 \\
transparent neutral face & -11.667 & 119.684 \\
without any figure & -81.667 & 134.761 \\
backward masking angry face & 10.000 & 193.203 \\
backward masking happy face & 21.667 & 160.331 \\
backward masking neutral face & 90.000 & 87.698 \\
\hline
\end{tabular}

A one-way analysis of variance was conducted to explore the impact of subthreshold signal on profit/loss value. The results showed that there were edge significant differences in participant's 
profit/loss value ( $\mathrm{p}=0.069)$. Follow-up pair wise comparisons(LSD Test)of these means yielded significant differences $(\mathrm{p}<0.05)$ between the group of backward masking happy face and the other three groups (transparent angry face, transparent happy face, transparent neutral face), among them, the group of backward masking happy face gain the most profit.

\section{Discussion and Conclusions}

Subliminal perception is a kind of unconscious perception, people can not consciously perceive. Plenty of studies have found that the level of unconscious processing is relatively low. That is to say, with the influence of unconscious perception, one can process the physical characteristics of the word, without understanding the meaning ${ }^{[3-5]}$. In our experiment, the presentation of subliminal stimuli was different from traditional unconscious stimuli forms, and a new method was tried. We made the visual stimuli unseen by adjusting the pictures transparency. In addition, the subliminal stimuli in our experiment persist for a long time far more than the traditional $17 \mathrm{~ms}$ or so. Comprehensively analyzing the experiment results, we found that subliminal emotional faces greatly influenced human's decision-making. Participants receiving the backward masking happy face were more inclined to choose red card and they gained the most profit, on the contrary, participants receiving the transparent neutral face are more inclined to choose black card and they lost the most money. Based on the results of this study, it was suggested that although all the participants do not see the emotional faces, but they are indeed significantly affected by those unseen information when making decision.

In summary, this paper indicates that subliminal vision stimuli provide a promising way to affect human's decision making. This finding has some particular meaning for the development of future decision making system, which will provide the scientific foundation for engineers. The function of current decision making system is to provide users with large amounts of data to support decision-making. The system mainly consists of human-machine interface and backstage database. The human-machine interface is responsible for providing a platform for users to communicate with the system, and human's operations or commands are accepted by it. The task of backstage database is data acquisition, analysis and information fusion ${ }^{[6]}$. According to the results of this study, we can imagine that the future decision support system is expected to systematically evaluate and change people's decision-making. It only needs engineers to embed a particular decision-making intervention module in the system; in addition, the function of intervention module can be flexibly set according to different intention.

\section{References}

[1] Brede M. (2013). Short versus long term benefits and the evolution of cooperation in the prisoner's dilemma game. PLoS One, 8(2), e56016.

[2] Normann HT., Wallace B. (2012). The impact of the termination rule on cooperation in a prisoner's dilemma experiment. International Journal of Game Theory, 41(3), 707-718.

[3] Richard L A, Greenwald A (2000). Parts outweigh the whole (word) in unconscious analysis of meaning. Psychological Science, 11, 2, 118-123.

[4] Dehaene S., Naccache L, et al (1998). Imaging unconscious semantic priming. Nature, 395, 597-600.

[5] Kouider S., Dehaene, S. (2007).Levels of processing during non-conscious perception: a critical review of visual masking. Philosophical Transactions of the Royal Society B: Biological Sciences, $362,1481,857-875$.

[6] Pratyush B., Abhijit C. (2004). An empirical investigation of decision-making satisfaction in web-based decision support systems. Decision support systems, 37(2): 187-197. 